\title{
Alcohol Consumption, Alcohol Outlets, and the Risk of Being Assaulted With a Gun
}

\author{
Charles C. Branas, Michael R. Elliott, Therese S. Richmond, Dennis P. Culhane \\ and Douglas J. Wiebe
}

\begin{abstract}
Background: We conducted a population-based case-control study to better delineate the relationship between individual alcohol consumption, alcohol outlets in the surrounding environment, and being assaulted with a gun.

Methods: An incidence density sampled case-control study was conducted in the entire city of Philadelphia from 2003 to 2006. We enrolled 677 cases that had been shot in an assault and 684 population-based controls. The relationships between 2 independent variables of interest, alcohol consumption and alcohol outlet availability, and the outcome of being assaulted with a gun were analyzed. Conditional logistic regression was used to adjust for numerous confounding variables.

Results: After adjustment, heavy drinkers were 2.67 times as likely to be shot in an assault when compared with nondrinkers $(p<0.10)$ while light drinkers were not at significantly greater risk of being shot in an assault when compared with nondrinkers. Regression-adjusted analyses also demonstrated that being in an area of high off-premise alcohol outlet availability significantly increased the risk of being shot in an assault by 2.00 times $(p<0.05)$. Being in an area of high on-premise alcohol outlet availability did not significantly change this risk. Heavy drinkers in areas of high off-premise alcohol outlet availability were 9.34 times $(p<0.05)$ as likely to be shot in an assault.

Conclusions: This study finds that the gun assault risk to individuals who are near off-premise alcohol outlets is about the same as or statistically greater than the risk they incur from heavy drinking. The combination of heavy drinking and being near off-premise outlets resulted in greater risk than either factor alone. By comparison, light drinking and being near on-premise alcohol outlets were not associated with increased risks for gun assault. Cities should consider addressing alcohol-related factors, especially off-premise outlets, as highly modifiable and politically feasible approaches to reducing gun violence.
\end{abstract}

Key Words: Violence, Injury, Alcohol, Alcohol Outlets, Geography, Epidemiology.

$\mathrm{P}$ REVENTION STRATEGIES THAT focus only on guns can be protracted with limited political support (Branas, 2006) and uncertain consequences (Kassirer, 1995; Teret and Wintemute, 1993; Wintemute, 1999; Zimring, 1991). Although the inappropriate use of guns is necessary to the occurrence of gun violence, there are other contributing but similarly modifiable factors that also warrant serious con-

From the Department of Biostatistics and Epidemiology, Firearm \& Injury Center at Penn, University of Pennsylvania School of Medicine $(C C B, D J W)$, Philadelphia, Pennsylvania; Department of Biostatistics, Institute for Social Research, University of Michigan School of Public Health (MRE), Ann Arbor, Michigan; Division of Biobehavioral and Health Sciences, Firearm \& Injury Center at Penn, University of Pennsylvania School of Nursing (TSR), Philadelphia, Pennsylvania; and Cartographic Modeling Laboratory, University of Pennsylvania School of Social Policy and Practice (DPC), Philadelphia, Pennsylvania.

Received for publication July 25, 2008; accepted December 21, 2008.

Reprint requests: Charles C. Branas, PhD, Department of Biostatistics and Epidemiology, University of Pennsylvania School of Medicine, Room 936 Blockley Hall, 423 Guardian Drive, Philadelphia, PA 19104-6021; Fax: 215-573-2265; E-mail: cbranas@upenn.edu

Copyright $(2) 2009$ by the Research Society on Alcoholism.

DOI: $10.1111 / \mathrm{j} .1530-0277.2009 .00912 . x$ sideration. Many of these other factors have the advantage of being less politically confrontational than guns and, as such, are more feasible opportunities for prevention in many communities.

One such modifiable factor is alcohol. People may place themselves at risk of becoming victims of gun violence by inappropriately consuming alcohol. People may also place themselves at risk of becoming victims of gun violence by entering environments where alcohol is being inappropriately consumed, regardless of whether they themselves are drinking. Although both personal and environmental factors are important, prevention resources are often limited and communities interested in pursuing alcohol-related prevention strategies to reduce gun violence must often choose to target either inappropriate consumption or environments that promote inappropriate consumption.

To assist these communities in gauging the relative value of different alcohol-related prevention strategies to reduce gun violence, we conducted a population-based case-control study of personal alcohol consumption, environmental alcohol outlet availability, and gun violence. We included both fatal and nonfatal outcomes and accounted for a variety of individual, situational, and environmental confounders. 


\section{MATERIALS AND METHODS}

The association of alcohol outlets and violence has been welldocumented using ecologic study designs. However, these prior ecologic studies suffer from aggregation biases and are unable to gauge the relative risks created for individuals when they consume alcohol or enter into environments where alcohol is being consumed, such as areas with high levels of alcohol outlet availability. There is a need for the application of study designs other than the traditional ecologic framework that has been used to date.

We applied a case-control study design to determine the association between alcohol consumption, alcohol outlets, and gun assault. Trial, cohort, and matched cohort designs were all considered but for various reasons (ethical considerations, prohibitively long implementation time, limited generalizability, etc.) were not pursued. To determine this in the most generalizable way, our target population was chosen to be residents of Philadelphia prompting the use of population-based controls. Use of other types of nonpopulationbased controls (dead controls, hospital-based controls, etc.) were considered but would have likely biased any final odds ratio estimates toward the null (Wiebe and Branas, 2003; Wiebe et al., 2004). Alternatively, use of control subjects who were assaulted by nongun means would not have been consistent with our target population and would have produced similarly biased estimates.

In applying the case-control design, we assumed that the resident population of Philadelphia risked being shot in an assault at any location and at any time of day or night. Disease-based, "immunity" restrictions were not employed (unlike other situations where such restrictions might be appropriate, i.e., you must be in a car to risk being injured as an occupant during a crash). This is a common approach for case-control studies (Poole, 1986, 1987, 1999) and an acceptable assumption because guns are mobile, potentially concealable items and the bullets they fire can pass through obstacles and travel long distances (Richmond et al., 2004). Any member of the general population has the potential to be exposed to guns and the bullets they discharge regardless of where they are or what they are doing. As such, we reasonably chose not to exclude subjects as "immune" from hypothetically becoming cases because they were, for instance, asleep at home during the night or at work in an office building during the day. Instead, we appropriately measured and controlled for locational and time-based situations that might have changed, but did not eliminate, the risk of being shot in an assault.

\section{Subject Identification and Matching}

Gunshot assault cases caused by powder charge guns were identified as they occurred, from October 15, 2003, to April 16, 2006. The final 6 months of this period were limited to only fatal cases. Because they function differently from gun assaults and were beyond the scope of the relationship we sought to investigate, self-inflicted, unintentional, police-related (an officer shooting someone or being shot), and gun injuries of undetermined intent were excluded. Individuals under 21 years of age were excluded because it was not legal for them to possess a gun in Philadelphia and, as such, the relationship we sought to investigate was functionally different enough to prompt separate study of this age group. We excluded individuals who were not residents of Philadelphia as they were not part of our target population. We excluded individuals not described as Black or White as they would have been a very small percentage of our subjects (less than $2 \%$ ). Even after these exclusions the study only needed a subset of the remaining shootings to test its hypotheses. A random number was thus assigned to these remaining shootings, as they presented, to enroll a representative one-third of them.

Data coordinators at the Philadelphia Police Department identified and enrolled new shooting cases as they occurred by reviewing an electronic incident tracking system and interviewing police officers, detectives, and medical examiners. Basic data for eligible cases were wirelessly sent to the University of Pennsylvania where study leaders forwarded them to a survey research firm for recruitment of a matched control. More detailed information for each enrolled case was later filled-in using additional data from police, medical examiners, emergency medical services, and hospital data sources (Branas et al., 2008).

Population-based controls were drawn from the target population of interest that was thought to have given rise to the cases, namely all community-dwelling (i.e., not institutionalized, not incarcerated, etc.) Philadelphia residents (Wacholder et al., 1992). These populationbased controls were a random sample of individuals at risk of being shot that would have been identified as cases had they been shot in Philadelphia. Controls were selected independent of their geographic location but were in Philadelphia at the time the case to which they were matched was shot. The median number of days between the time a shooting occurred and the time a control interview was completed was 2, with over three-quarters of all control interviews being completed within 4 days of their matched shooting. Controls were interviewed as rapidly as possible to minimize recall bias.

We used incidence density sampling, a common approach to casecontrol studies (Rothman and Greenland, 1998), to essentially pairmatch our cases and controls on the date and time (within 30-minute periods, i.e., 10:30 PM, 11:00 PM) of each shooting. We did this because the factors we planned to analyze, including alcohol consumption and being near alcohol outlets, were often short-lived making the time of the shooting most etiologically relevant (Roberts, 1995). This also helped to control for a great many unmeasurable confounders that were related to time - hour of the day, day of the week, season of the year, etc. Prior case-control work on gun injury (Kellermann et al., 1993) as well as other early injury case-control studies (Haddon et al., 1961), have pair-matched cases and controls on location, something that we purposely did not do because it would have likely produced bias toward the null due to overmatching (alcohol consumption is potentially related to location) and we also wanted to study the effects of location with respect to alcohol outlets (Branas et al., 2008). We appropriately chose to adjust for unmatched factors, such as location, using statistical regression modeling even though our case and control subject groups appeared to be different with respect to many of these factors (Rothman and Greenland, 1998).

However, certain basic factors were thought to be appropriate for pair-matching of our cases and controls based on a priori justifications of statistical inefficiency (i.e., too few subjects for analysis in certain matched strata). When appropriate, pair-matching is most practical using select nominal scale confounders and those with a large number of possible values per stratum (Rothman and Greenland, 1998). Our controls were thus matched to cases based on agegroup (21-24, 25-39, 40-64, and over 65 years old), gender, and race (Black or White). Rather than adjust for them in our analysis, we pair-matched on these variables to avoid extremely sparse data in certain subgroups given our prior knowledge that exceedingly different age, race, and gender distributions existed among assaultive shootings relative to the general population of Philadelphia. Based on early power calculations, 1 control was matched to each shooting case.

Controls were sampled from all of Philadelphia using random digit dialing (Waksberg, 1978; Weiner et al., 2007). The protocol allowed for controls who later were shot to remain eligible for inclusion in the study as cases (Rothman and Greenland, 1998). In the interest of time, multiple interviewers may have simultaneously begun and then completed control interviews. This resulted in 7 cases that had more than 1 control. These few additional controls were retained in final analyses. We also tested for the possibility that multiple telephone lines and age-gender-race-eligible members of a household could lead to unequal probabilities of selection among the control subjects. Case weights equal to the inverse of the probability of selection were constructed, and weighted conditional logistic regression analyses were conducted in parallel with unweighted analyses. Little difference 
$(<5 \%)$ was found between the weighted and unweighted analyses; thus, unweighted analyses are reported.

We took several steps to maximize participation and avoid selection biases due to nonresponse (Harlow et al., 1993; Herzog and Rodgers, 1992; Koepsell et al., 1996; Weiner et al., 2007). Using standard formulae, the cooperation rate for our control survey was calculated to be $74.4 \%$ and the response rate $56.0 \%$ (Daves, 2006). These rates exceeded those of other surveys conducted at about the same time (Galea and Tracy, 2007) and were high enough to produce a reasonably representative sample of our target population (Groves, 2006; Keeter et al., 2006). Within the age, race, and gender categories on which we matched, our control respondents were also statistically similar to the general population of Philadelphia in terms of marital status, retirement, education, general health status, and smoking status within the age, gender, and race categories specified above. Our controls were however found to be unemployed significantly more often than the general population.

\section{Conceptual Framework and Variables}

Numerous variables are influential as confounders in the association between victim alcohol consumption, proximity to alcohol outlets, and gun assault. Confounding variables can be conceptually separated into individual and situational characteristics, both of which feed the eventual victim-offender interaction that results in gun assault (Felson and Steadman, 1983; Wells, 2002; Ziegenhagen and Brosnan, 1985).

Based on previous work and theory, we measured and adjusted for numerous individual and situational characteristics (Table 1). Individual characteristics included age, race, gender, ethnicity, unemployment, education, and arrest history. Situational characteristics included those specific to the victims themselves at the time they were assaulted: whether they had consumed alcohol, were outdoors, or had others present. We also accounted for situational characteristics specific to the neighborhood within which the gun assault occurred: its alcohol outlet availability, racial and ethnic make-up, unemployment and income levels, and concentration of arrests for illicit drug trafficking (Gruenewald, 2007; Islam et al., 2003; Kellermann et al., 1993; Kleck and Gertz, 1998; Kleck and McElrath, 1991; Livingston et al., 2007; McCord and Ratcliffe, 2007; Reedy and Koper, 2003; Warner and Wilson Coomer, 2003; Ziegenhagen and Brosnan, 1985).

The use of an incidence density sampling design accounted for many time-based confounders related to the victim-offender interaction (Rothman and Greenland, 1998). In addition, the individuallevel characteristics that we measured carried forward into the assault itself as did many situational characteristics. These situational characteristics included measures that likely served to redistribute power between victim and offender (such as substance use and having others present) and locational measures that likely influenced the interaction between victim and offender (such as being outdoors or in various neighborhood conditions) (Felson and Steadman, 1983; Wells, 2002; Ziegenhagen and Brosnan, 1985). Cases were also classified as fatal gun assaults to permit subset analyses of gun assault risk.

\section{Data and Analyses}

Individual and environmental-level data were obtained from local, state, and national sources under approval from both the University of Pennsylvania and the Philadelphia Department of Public Health Institutional Review Boards. A federal certificate of confidentiality was also provided by the National Institutes of Health.

For cases, alcohol consumption at the time of the shooting was determined by blood alcohol concentrations from emergency departments and the morgue and, when these were not available, by police observation, which has been shown to be effective in distinguishing intoxicated drinkers (Brick and Carpenter, 2001; Grossman et al., 1996; Moskowitz et al., 1999; Soderstrom et al., 1994; Stuster and
Table 1. Comparing Cases and Controls in Terms of Situational and Individual Characteristics

\begin{tabular}{|c|c|c|c|c|}
\hline & \multicolumn{2}{|c|}{ All gun assaults } & \multicolumn{2}{|c|}{$\begin{array}{l}\text { Fatal gun } \\
\text { assaults }\end{array}$} \\
\hline & Cases & Controls & Cases & Controls \\
\hline \multicolumn{5}{|l|}{ Situational characteristics } \\
\hline \multicolumn{5}{|l|}{ Alcohol consumption (\%) } \\
\hline No drinking & 73.6 & 86.2 & 75.6 & 86.0 \\
\hline Light drinking & 18.8 & 11.7 & 16.2 & 12.2 \\
\hline Heavy drinking & 7.6 & 2.1 & 8.2 & 1.8 \\
\hline \multicolumn{5}{|l|}{ Alcohol outlet availability (\%) } \\
\hline Low & 49.3 & 50.8 & 52.4 & 50.1 \\
\hline High & 50.7 & 49.2 & 47.6 & 49.9 \\
\hline Low on-premise & 48.7 & 51.4 & 51.8 & 51.2 \\
\hline High on-premise & 51.3 & 48.6 & 48.2 & 48.8 \\
\hline Low off-premise & 46.5 & 54.1 & 49.9 & 53.6 \\
\hline High off-premise & 53.5 & 46.0 & 50.1 & 46.4 \\
\hline Being outdoors (\%) & 83.1 & 9.1 & 70.8 & 9.2 \\
\hline $\begin{array}{l}\text { Others present (mean } \\
\text { number of people) }\end{array}$ & 3.1 & 2.9 & 3.3 & 2.9 \\
\hline \multicolumn{5}{|l|}{ Surrounding area } \\
\hline $\begin{array}{l}\text { Blacks (mean 1,000 } \\
\text { people/mile) }\end{array}$ & 26.0 & 20.2 & 24.4 & 20.6 \\
\hline $\begin{array}{l}\text { Hispanics (mean 1,000 } \\
\text { people/mile) }\end{array}$ & 4.5 & 2.7 & 4.2 & 2.9 \\
\hline $\begin{array}{l}\text { Unemployment (mean } \\
1,000 \text { people/mile) }\end{array}$ & 2.4 & 2.0 & 2.3 & 2.0 \\
\hline $\begin{array}{l}\text { Income (mean million } \\
\text { dollars/mile) }\end{array}$ & 594.9 & 652.8 & 577.1 & 632.3 \\
\hline $\begin{array}{l}\text { Illicit drug trafficking } \\
\text { (mean arrests/mile) }\end{array}$ & 953.2 & 563.6 & 809.9 & 634.2 \\
\hline \multicolumn{5}{|l|}{ Individual characteristics } \\
\hline Age (mean years) & 30.6 & 32.7 & 32.0 & 34.1 \\
\hline Black (\%) & 87.9 & 87.9 & 87.7 & 87.3 \\
\hline Male (\%) & 91.9 & 91.7 & 91.4 & 91.5 \\
\hline Hispanic (\%) & 7.2 & 3.5 & 7.6 & 4.2 \\
\hline Unemployed (\%) & 33.0 & 18.9 & 38.0 & 19.4 \\
\hline Education (mean years) & 11.6 & 12.7 & 11.7 & 12.7 \\
\hline Prior arrests (\%) & 53.1 & 37.1 & 54.6 & 36.0 \\
\hline
\end{tabular}

Burns, 1998; van Wijngaarden et al., 1995). For controls, alcohol consumption at the time of the shooting was determined via a series of questions that anchored recall and determined recency of drinking, rate of drinking, and number of drinks (defined as 1 bottle, can, or glass of beer, 1 glass of wine, 1 mixed drink, or 1 shot of liquor). Cases and controls were separated into nondrinkers, light drinkers [blood alcohol concentration (BAC) $<0.10 \mathrm{mg} / \mathrm{dl}$ or its gender/height/ weight-adjusted drink equivalent], and heavy drinkers (BAC $\geq 0.10 \mathrm{mg} / \mathrm{dl}$ or its gender/height/weight-adjusted drink equivalent). Alcohol consumption was determined for $90.0 \%$ of cases and $99.7 \%$ of controls and locations were obtained for $99.3 \%$ of cases and $95.9 \%$ of controls. Missing data were imputed using multiple imputation by chained equations (van Buuren et al., 1999; Rubin, 1987).

All environmental data were linked to a given case subject according to their location when the shooting occurred, and for control subjects, according to where the control was located at the time their matched case subject was shot. We geographically coded subject locations to latitude and longitude points using intersections or block faces and alcohol outlet locations to latitude and longitude points using actual addresses. On-premise (such as bars and taverns) and off-premise (such as take-out establishments and delis) alcohol outlets were classified using liquor licenses and North American Industry Classification System codes obtained for each alcohol outlet in Philadelphia.

To corroborate our classifications, 2 pairs of field observers also visited a randomly selected group of 70 alcohol outlets from across 
Philadelphia on Thursday and Friday nights between 8 PM and midnight. Based on prior work (Graham and Homel, 1997; Graham et al., 1980; Quigley et al., 2003; Wolfson et al., 1996) a structured data collection procedure was also developed and implemented to systematically observe alcohol outlet patrons, staff, drinking environments, and nearby areas. We did not conduct statistical analyses using this relatively small number of outlets but were able to complete important and complementary qualitative assessments of alcohol outlets in better explaining our statistical findings. Other environmental factors were geographically coded using the latitude and longitude centroid and population-weighted centroid points of blocks, block groups, and tracts.

Case and control subjects were assigned inverse distance-weighted (IDW) measures of their cumulative exposure to environmental factors based on the points where the subjects were located and the point locations and magnitudes of the environmental factors surrounding them. The higher the IDW measure, $Z_{\mathrm{G}}$, the greater the clustering and magnitude of environmental factors around a subject's location as given by:

$$
Z_{\mathrm{G}}=\sum_{\mathrm{ij}}\left(s_{\mathrm{j}} / e^{d \mathrm{ij}}\right) \forall d_{\mathrm{ij}}<\theta, i \in I, j \in J
$$

where $s_{\mathrm{j}}$ reflects the presence or size (i.e., alcohol sales volume) of an environmental factor at location $j, \mathrm{~d}_{i j}$ is the point-to-point rectilinear distance between subject $i$ and environmental factor $j$, $\theta$ is a bandwidth beyond which all values are assumed to be zero, $I$ is the set of all case or control subject locations, and $J$ is the set of all environmental factor locations. Inverse exponentiated distances prevented undefined fractions due to zero distances (i.e., subjects in bars) and greatly de-emphasized environmental factors that were far away from subjects. Rectilinear distance metrics, as opposed to Euclidean straight-line distance metrics, were used to better estimate the urban environment. The bandwidth value, $\theta$, was set at 2 miles for all environmental factors based on standard cross-validation techniques (Fotheringham et al., 2000; Silverman, 1978, 1986) and a heuristic that incorporates the number of observed points under study scaled to the square root of the study area, in this case the city of Philadelphia (Bailey and Gattrell, 1995; Williamson et al., 1998). Separate $Z_{\mathrm{G}}$ measures were calculated for cases and controls and then compared (Fig. 1).

Inverse distance-weighted measures have a long history of use by geographers and offered our analysis several important advantages over simply assigning subjects to solitary geographic polygons, such as census tracts or block groups. Analyses in which subjects are nested within solitary administrative geographic units (i.e., a single census tract or block group) can generate challenges, including the overestimation of effects (Geronimus, 2006; Holt et al., 1996; Krieger et al., 2002; Openshaw, 1984; Scribner, 2000; Wong, 1991; Wrigley, 1995). Oftentimes, the boundaries of these administrative geographic units have been determined for purposes other than the specific relationships under study and as such may be awkwardly shaped, poorly correspond to lived space, have edge-effects (i.e., a subject assigned to a tract but located on its border may be more influenced by their neighboring tract), or impose a neighborhood scale that is inappropriate for the subjects being studied (Geronimus, 2006; Holt et al., 1996; Krieger et al., 2002; Openshaw, 1984; Scribner, 2000; Wong, 1991; Wrigley, 1995). For these reasons, we chose to use IDW measures which were continuous and essentially boundary-free.

The IDW measures we used essentially assigned each subject their own unique neighborhood, avoided aggregation effects by design and needed no multilevel or clustering adjustments (Longley et al., 2005) while directly accounting for spillover effects and the variability of neighboring areas (Geronimus, 2006; Holt et al., 1996; Krieger et al., 2002; Openshaw, 1984; Scribner, 2000; Wong, 1991; Wrigley, 1995). These measures were calculated for alcohol outlets and all other environmental factors. Gravity measures for alcohol outlets were also separated into high and low availability using case and control subject median cut-points. For alcohol outlets, these categorical gravity measures were more readily interpretable and used to create interaction terms with subject alcohol consumption.

Individual and environmental-level independent variables were compared for cases and controls followed by conditional logistic regression models (Breslow, 1996) of the focal independent variables alcohol consumption and alcohol outlet availability and the outcome of gun assault. Individual and environmental-level confounders were selected because they were of theoretical importance, could be measured within the scope of our study, had been used in prior studies (Cummings et al., 1997; Dahlberg et al., 2004; Decker and Caldwell, 1997; Grassel et al., 2003; Kellermann et al., 1993; Kleck, 1998; Kleck and DeLone, 1993; Kleck and Gertz, 1995, 1998; McCord and Ratcliffe, 2007; Nelson et al., 1996; Warner and Wilson Coomer, 2003; Wiebe, 2003) and were sufficiently noncollinear. Excessively collinear confounders were excluded by keeping variance inflation factors under 10 (Fox, 1991).

All regression models were adjusted for yearly age (because, even after matching on categorical age, there was still residual confounding due to the effect of continuous age within categories, as cases were younger than controls by a statistically significant mean difference of over 2 years, $p<0.01$; Rothman and Greenland, 1998) and
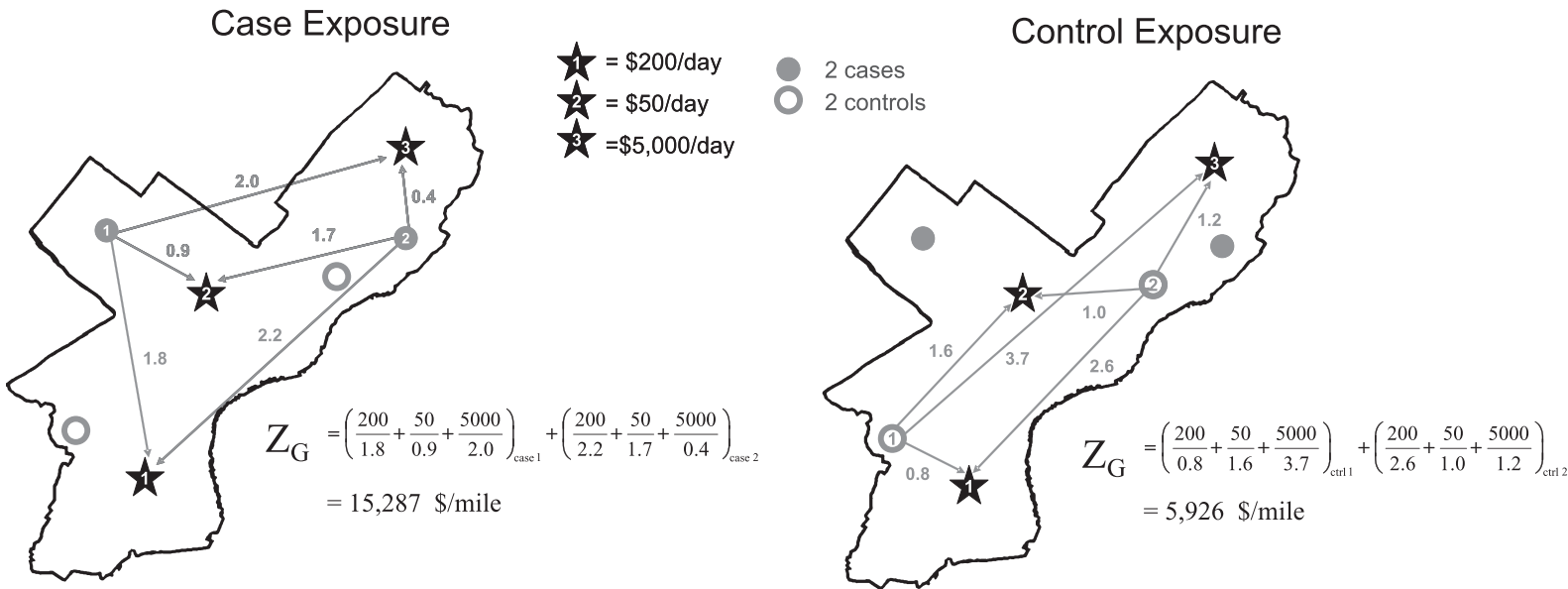

Fig. 1. Philadelphia maps showing point-to-point inverse distance-weighted exposure calculations $\left(Z_{G}\right)$ for 4 hypothetical cases and controls and 3 hypothetical alcohol outlets with their daily sales; the $Z_{G}$ of cases is about 2.5 times that of controls. 
all other confounders that were not excessively collinear. Robust sandwich estimators of variance were also specified (White, 1980) and the residuals from our regression models were not found to be statistically significant for spatial autocorrelation (using Moran's $I$ and Geary's $c$ coefficients) (Getis, 2000; Gruenewald and Remer, 2006). Statistically significant findings were taken to be those with $p<0.05$ throughout our analyses.

\section{RESULTS}

\section{Study Participants}

Over the study period, our research team was notified about 3,485 shootings of all types occurring in Philadelphia. This translated into an average of $4.77 \pm 2.82$ shootings per day with a maximum of 21 shootings in a single day and an average of 9 days a year that were shooting-free. From among all these shootings, 3,202 (91.88\%) were assaults, 167 were self-inflicted $(4.79 \%), 60$ were unintentional $(1.72 \%), 54$ were legal interventions $(1.55 \%)$, and 2 were of undetermined intent $(0.06 \%)$. When considering only assaults, an average of $4.39 \pm 2.70$ individuals were shot per day in Philadelphia with a maximum of 20 in a single day and an average of 13 days a year in which no individuals were shot.

From among all 3,202 individuals who had been shot in an assault, we excluded those under 21 years of age or of unknown age $(29.83 \%)$, non-Philadelphia residents $(4.34 \%)$, individuals not described as being Black or White $(1.62 \%)$, and police officers that had been shot $(0.09 \%)$. From the remaining group of 2,073 participants, $677(32.66 \%)$ were randomly selected and enrolled. An age, race, and gendermatched group of 684 control participants were also concurrently identified and enrolled.

Among all 677 enrolled shooting assaults, the case-fatality rate was $18.54 \%$. Cases and controls showed no statistically significant differences in terms of their age, race, and gender distributions. As evidence that our incidence density sampling was successful, cases and controls also showed no statistically significant differences in terms of the times of day, days of the week, and months of the year when their data were collected. Cases and controls were thus successfully matched on age, race, gender, and time.

However, when compared with controls, shooting cases were more often Hispanic, more unemployed, less educated, and had a greater frequency of prior arrest. At the time of the shooting, cases were also more often outdoors, in a crowd, and closer to areas where more Blacks, Hispanics, unemployed, and lower income individuals resided (Table 1).

\section{Alcohol Consumption, Alcohol Outlet Availability, and Gun Assault}

Unadjusted comparisons showed that cases were drinking and heavily drinking significantly more than controls and were significantly more often in areas of high off-premise alcohol outlet availability than controls $(p<0.01)$. Similar comparisons were noted among fatal gun assaults (Table 1).
Table 2. Regression Results of the Associations Between Alcohol Consumption, Alcohol Outlet Availability, and Gun Assault

\begin{tabular}{|c|c|c|}
\hline & All gun assaults & Fatal gun assaults \\
\hline \multicolumn{3}{|l|}{ Alcohol consumption } \\
\hline No drinking & 1.00 & 1.00 \\
\hline Drinking & $1.33[0.54,3.31]$ & $0.32[0.03,3.11]$ \\
\hline No drinking & 1.00 & 1.00 \\
\hline Light drinking & $1.16[0.42,3.22]$ & $0.27[0.02,2.97]$ \\
\hline Heavy drinking & $2.67[0.90,7.87]^{\star}$ & $6.20[0.42,92.47]$ \\
\hline \multicolumn{3}{|c|}{ Alcohol outlet availability } \\
\hline Low & 1.00 & 1.00 \\
\hline High & $1.22[0.59,2.52]$ & $0.74[0.20,2.79]$ \\
\hline Low on-premise & 1.00 & 1.00 \\
\hline High on-premise & $1.12[0.57,2.21]$ & $0.85[0.27,2.67]$ \\
\hline Low off-premise & 1.00 & 1.00 \\
\hline High off-premise & $2.00[1.05,3.75]^{\star *}$ & $4.19[0.81,21.78]^{\star}$ \\
\hline
\end{tabular}

Models adjusted for all characteristics listed in Table 1. Adjusted odds ratios and $95 \%$ confidence intervals with ${ }^{*} p<0.10$ and ${ }^{* *} p<0.05$.

Regression-adjusted analyses demonstrated that light drinkers were not at significantly greater risk of being shot in an assault when compared with nondrinkers. Heavy drinkers, on the other hand, were 2.67 times as likely to be shot in an assault compared with nondrinkers $(p<0.10)$. These relationships were similar among fatal gun assaults (Table 2).

Regression-adjusted analyses also demonstrated that being in an area of high alcohol outlet availability did not significantly change the risk of being shot in an assault. This finding also persisted among fatal gun assaults. In addition, being in an area of high on-premise alcohol outlet availability did not significantly change the risk of being shot in an assault or a fatal gun assault (Table 2).

Our regression analyses did, however, demonstrate that being in an area of high off-premise alcohol outlet availability significantly increased the risk of being shot in an assault by 2.00 times $(p<0.05)$. The risk of being fatally shot in an assault was even higher, 4.19 times more while in an area of high off-premise alcohol outlet availability $(p<0.10)$ (Table 2).

The testing of interaction terms showed that the greatest, statistically significant risk of being shot in an assault was among heavy drinkers who were also in areas of high offpremise alcohol outlet availability. Heavy drinkers in areas of high off-premise alcohol outlet availability had 9.34 times the gun assault risk of nondrinkers in areas of low off-premise alcohol outlet availability $(p<0.05)$. Although less pronounced, light drinkers in areas of high off-premise alcohol outlet availability had 2.29 times the gun assault risk of nondrinkers in areas of low off-premise alcohol outlet availability $(p<0.05)$. These same interactions were not statistically significant for drinkers in areas of high on-premise alcohol outlet availability (Table 3).

The 70 randomly selected alcohol outlets we visited were located within 15 different Philadelphia neighborhoods. Among 62 outlets that were open when we visited, $74.2 \%$ were on-premise and $25.8 \%$ were off-premise establishments. 
Table 3. Regression Results of the Interaction Effects Between Alcohol Consumption and Alcohol Outlet Availability on the Risk of Being Injured in a Gun Assault

\begin{tabular}{ll}
\hline & All gun assaults \\
\hline All alcohol outlets & \\
No drinking, low availability & 1.00 \\
No drinking, high availability & $1.38[0.29,6.52]$ \\
Light drinking, low availability & $1.25[0.28,5.56]$ \\
Light drinking, high availability & $1.26[0.55,2.92]$ \\
Heavy drinking, low availability & $3.81[0.36,40.64]$ \\
Heavy drinking, high availability & $3.24[0.37,28.66]$ \\
On-premise outlets & \\
No drinking, low availability & 1.00 \\
No drinking, high availability & $1.17[0.29,4.76]$ \\
Light drinking, low availability & $1.31[0.29,5.92]$ \\
Light drinking, high availability & $1.18[0.54,2.56]$ \\
Heavy drinking, low availability & $3.46[0.39,30.90]$ \\
Heavy drinking, high availability & $3.03[0.35,22.91]$ \\
Off-premise outlets & \\
No drinking, low availability & 1.00 \\
No drinking, high availability & $1.34[0.30,6.00]$ \\
Light drinking, low availability & $2.09[0.49,8.88]$ \\
Light drinking, high availability & $2.29[1.08,4.83]^{\star *}$ \\
Heavy drinking, low availability & $1.41[0.16,12.12]$ \\
Heavy drinking, high availability & $9.34[1.02,86.10]^{\star *}$ \\
\hline
\end{tabular}

Models adjusted for all characteristics listed in Table 1. Adjusted odds ratios and $95 \%$ confidence intervals with ${ }^{*} p<0.10$ and ${ }^{* *} p<0.05$.

On-premise outlets typically had larger physical premises, more staff, and more crowding than off-premise outlets. Offpremise outlets were typically smaller, with one or maybe 2 staff, in more impoverished neighborhoods and more often with brighter lighting, "bulletproof" glass barriers and other security features than on-premise outlets.

\section{DISCUSSION}

After adjusting for numerous confounding factors, drinking alcohol was a risk factor for being shot in an assault although this risk was not statistically significant and was effectively limited to heavy drinkers. As is well known, heavily consuming alcohol can greatly lower inhibitions, increase confidence, and potentially release violent impulses (David and Spyker, 1979; Romelsjo, 1995). Otherwise noncombative individuals may overreact to perceived threats and instigate violent situations due to alcohol-impaired judgment of verbal and nonverbal social cues (Collins and Messerschmidt, 1993; Pernanen, 1991). Potential victims who are intoxicated are also potentially more vulnerable targets for predatory crimes such as homicide (Goodman et al., 1986).

By comparison, light drinkers were at about the same risk of being shot in an assault as nondrinkers. This suggests that alcohol consumption in moderation may not be a risk factor for violent victimization. Even though they had consumed, light drinkers likely retained enough clear judgment and perception to keep their risk in check when compared with heavy drinkers. Light drinkers may have reacted more appropriately to potentially violent situations or reduced their attractiveness as the targets of would-be violent offenders through various safety countermeasures that heavy drinkers were unable to exploit.

Alcohol outlet availability was also associated with a statistically significant risk of being shot in an assault, but only when considering areas where off-premise alcohol outlets, such as take-outs and delis, were highly available. The risk of being shot in an assault was most significant for heavy drinkers who were in neighborhoods where off-premise alcohol outlets were highly available. In many neighborhoods at night, these off-premise outlets were a center of activity, often providing the only well-lit spaces among nonworking street lamps, vacant properties, and dark residences, and being reasonably well trafficked with a steady interchange of patrons.

Off-premise outlets may have generated risks by promoting consumption of high-quantity, high-alcohol content beverages in bright but unattended spaces that were connected to the street where over $80 \%$ of assaultive shooting cases occurred. The gun assault risks posed by off-premise outlets also extended to otherwise uninvolved, but nearby individuals who were shot as bystanders. These risks were also likely compounded by a very small number of staff at off-premise outlets who frequently worked from behind fortified walls of "bulletproof" glass, and only briefly interacted with patrons to distribute alcohol and small food items. Some off-premise staff was even equipped to sleep overnight at their businesses and avoid emerging from behind their protective barriers until they felt safe in the morning.

Unlike off-premise alcohol outlets, on-premise outlets, such as bars and taverns, were by comparison highly monitored, relatively safe havens, even in neighborhoods with high levels of gun violence. The nomenclature of "violent bars" has generally been used to differentiate on-premise outlets that attract certain clientele who may be predisposed to violence (Graham et al., 2006; Quigley et al., 2003; Treno et al., 2007). Based on our findings, off-premise outlets can be differentiated in this way, attracting heavy drinkers and possibly other at-risk patrons differently than on-premise bars and taverns. Signage prohibiting "fighting" or "drug dealing" in off-premise outlets were markers of these at-risk patrons (Gruenewald, 2007; McCord and Ratcliffe, 2007). Lax monitoring of potentially at-risk patrons and a generally antisocial environment in offpremise outlets may have thus led to greater gun violence. Individuals in and around off-premise alcohol outlets were shot as the victims of predatory crimes, possibly because they had heavily consumed and were easier targets (Goodman et al., 1986), or they were shot as the victims of otherwise tractable arguments that became violent because one or more of the combatants had consumed alcohol.

Assaultive gun violence might be prevented if certain aspects of off-premise alcohol outlets began to function more like their on-premise counterparts. Training off-premise servers to cut-off heavy drinkers and promptly report the outbreak of arguments to police could be effective gun violence reduction strategies. Other approaches to reducing gun violence may include a general rezoning or reduction of offpremise outlet availability (Ashe et al., 2003; Holder et al., 
2000) and/or enhanced policing of public drunkenness in neighborhoods where off-premise outlets are highly clustered. It has been argued that areas with highly clustered alcohol markets reduce the unit price of alcohol through enhanced competition, thereby increasing consumption, the outdoors movement of patrons between alcohol outlets, and disturbances such as public drunkenness, litter, and noise. These phenomena may increase the likelihood of violence and make server interventions more difficult (Livingston et al., 2007). As such, an intervention to train servers at off-premise outlets should likely begin with some consideration of reducing the overall density of off-premise outlets in the surrounding area.

\section{Prior Ecologic Studies}

Prior ecologic work has shown that alcohol-induced violence is affected by the environmental context in which drinking occurs. Areas with high numbers of alcohol outlets have also been shown by some studies to also have high levels of violence, especially in terms of aggression, criminal victimization, assault, and homicide (Britt et al., 2005; Gruenewald and Remer, 2006; Livingston, 2008; Scribner et al., 1995; Speer et al., 1998; Treno et al., 2007).

In explaining this ecologic association, it has been posited, for instance, that individuals who choose to consume alcohol because they are in bars or on street corners may act more aggressively in the absence of home and family restraints (MacAndrews and Edgerton, 1969; Parker and Rebhun, 1995). Other ecologic studies have shown that areas with high numbers of on-premise alcohol outlets can also be risky, possibly because patrons and proprietors have cash on hand and, as such, attractive victims (Roncek and Bell, 1982; Roncek and Maier, 1991; Scribner et al., 1995). Still other ecologic studies have shown that areas with high numbers of offpremise alcohol outlets, selling "to-go" liquor in large quantities, chilled, and ready for immediate consumption on a street corner or in a nearby park or car, are also strongly associated with violence (Alaniz et al., 1998; Gruenewald and Remer, 2006; Gruenewald et al., 2006; Scribner et al., 1995, 1999).

Some ecologic studies have, however, failed to find strong associations between alcohol outlets and assaultive violence (Dull and Giacopassi, 1988; Gorman et al., 1998a,b; Livingston et al., 2007). These studies underscore the lack of a conclusive body of evidence regarding alcohol outlets and assaultive violence and point to the need for analyses using study designs other than the traditional ecological framework that directly measure individual as well as contextual risks (Morgenstern, 1998; Stevenson and McClure, 2005). It is for these reasons that the current case-control study was undertaken.

\section{Study Limitations}

A number of study limitations deserve discussion. Our control population was more unemployed than the target population of Philadelphians that it was to intended to represent.
Although we did account for employment status in our regression models and our control population was found to be representative of Philadelphians for 5 other indicators, having a preponderance of unemployment among our controls may mildly erode our study's generalizability. It is also worth noting that our findings are possibly not generalizable to nonurban areas whose gun injury risks can be significantly different than those of urban centers like Philadelphia (Branas et al., 2004).

Certain other variables that may have confounded the association between alcohol consumption, alcohol outlets and gun assault may have been omitted in our analysis. Given that this was not a randomized trial of alcohol consumption, alcohol outlets, and gun assault, the possibility of bias from unmeasured confounding, inherent in all observational study designs (including the case-control), was present. We have endeavored to control for this bias by carefully selecting and including a number of confounding variables. Even with the possibility of unmeasured confounding however, the casecontrol design used here improves upon prior ecologic study designs that infer individual level risks from aggregations of individuals and thus likely experience greater unmeasured confounding.

We did not enroll nongun assaults and cannot judge the association between alcohol consumption, alcohol outlets, and the risk of being assaulted in general and/or compare the associations between alcohol consumption, alcohol outlets, and the risks of being assaulted with a gun as opposed to a nongun weapon. Although these would have been useful comparisons to make, collection of nongun assault information was not pursued because it was seen as a considerably more challenging data collection endeavor given that shootings were much better defined and monitored by the police and medical systems in Philadelphia.

Finally, certain aspects of the victim-offender interaction that occurred at the time of a gun assault were not possible for us to reliably measure for both cases and controls. The use of an incidence density sampling design did, however, potentially account for many time-based confounders related to the victim-offender interaction (Rothman and Greenland, 1998). In addition, the individual-level characteristics that we measured carried forward into the assault event itself as did many situational characteristics.

\section{CONCLUSION}

This study finds that the gun assault risk to individuals who are near off-premise alcohol outlets is about the same as or statistically greater than the risk they incur from heavy drinking. The combination of heavy drinking and being near off-premise outlets resulted in far greater risk than either factor alone. By comparison, light drinking and being near onpremise alcohol outlets were not associated with increased risks for gun assault. The current study corroborates some aspects of prior ecologic work but also uncovers new information about the relationships between alcohol consumption, 
alcohol outlets, and gun violence. Cities should consider addressing alcohol-related factors, especially off-premise outlets, as highly modifiable and politically feasible approaches to reducing gun violence.

\section{ACKNOWLEDGMENT}

Funded by the National Institutes of Health, National Institute on Alcohol Abuse and Alcoholism (under grant number R01AA013119). The authors are also indebted to numerous dedicated individuals at the Philadelphia Police, Public Health, Fire and Revenue Departments as well as DataStat, Inc., who collaborated in this work. The authors have no conflicts of interest related to this manuscript.

\section{REFERENCES}

Alaniz M, Cartmill R, Parker R (1998) Immigrants and violence: the importance of a neighborhood context. Hisp J Behav Sci 20:155-174.

Ashe M, Jernigan D, Kline R, Galaz R (2003) Land use planning and the control of alcohol, tobacco, firearms, and fast food restaurants. Am J Public Health 93:1404-1408.

Bailey TG, Gattrell AC (1995) Interactive Spatial Data Analysis. PrenticeHall, London.

Branas C (2006) [Review of] Suing the gun industry: A battle at the crossroads of gun control and mass torts. J Leg Med 27:103-108.

Branas CC, Richmond TS, Culhane DP, Wiebe DJ (2008) Novel linkage of individual and geographic data to study firearm violence. Homicide Stud $12,298-320$.

Branas CC, Nance ML, Elliott MR, Richmond TS, Schwab CW (2004) Urban-rural shifts in intentional firearm death: different causes, same results. Am J Public Health 94:1750-1755.

Breslow NE (1996) Statistics in epidemiology: the case-control study. J Am Stat Assoc 91, 14-28.

Brick J, Carpenter JA (2001) The identification of alcohol intoxication by police. Alcohol Clin Exp Res 25:850-855.

Britt H, Carlin B, Toomey T, Wagenaar A (2005) Neighborhood level spatial analysis of the relationship between alcohol outlet density and criminal violence. Environ Ecol Stat 12:411-426.

van Buuren S, Boshuizen HC, Knook DL (1999) Multiple imputation of missing blood pressure covariates in survival analysis. Stat Med 18:681-694.

Collins J, Messerschmidt M (1993) Epidemiology of alcohol-related factors. Alcohol Health Res World 17:93-100.

Cummings P, Koepsell T, Grossman D, Savarino J, Thompson R (1997) The association between the purchase of a handgun and homicide or suicide Am J Public Health 87:974-978.

Dahlberg LL, Ikeda RM, Kresnow MJ (2004) Guns in the home and risk of a violent death in the home: findings from a national study. Am J Epidemiol 160:929-936.

Daves R (2006) Standard Definitions: Final Dispositions of Case Codes and Outcome Rates for Surveys, 4th edn. The American Association for Public Opinion Research, Lenexa, KS.

David DJ, Spyker DA (1979) The acute toxicity of ethanol: dosage and kinetic nomograms. Vet Hum Toxicol 21:272-276.

Decker S, Caldwell A (1997) Illegal Firearms: Access and Use by Arrestees. National Institute of Justice, Washington, DC.

Dull RT, Giacopassi DJ (1988) Dry, damp, and wet: correlates and presumed consequences of local alcohol ordinances. Am J Drug Alcohol Abuse 14:499-514

Felson R, Steadman H (1983) Situational factors in disputes leading to criminal violence. Criminology 21:59-74.

Fotheringham AS, Brunsdon C, Charlton M (2000) Quantitative Geography. Perspectives on Spatial Data Analysis. Sage, London.
Fox J (1991) Regression diagnostics: an introduction, in Sage University Paper Series on Quantitative Applications in the Social Sciences, pp 7-79. Sage, Newbury Park, CA.

Galea S, Tracy M (2007) Participation rates in epidemiologic studies. Ann Epidemiol 17:643-653.

Geronimus AT (2006) Invited commentary: using area-based socioeconomic measures - think conceptually, act cautiously. Am J Epidemiol 164:835840.

Getis A (2000) Spatial statistics, in Geographical Information Systems Volume 1 Principles and Technical Issues, 2nd edn (Longley P, Goodchild M, Maguire D, Rhind D eds), pp 239-251. John Wiley and Sons, Chichester, England.

Goodman RA, Mercy JA, Loya F, Rosenberg ML, Smith JC, Allen NH, Vargas L, Kolts R (1986) Alcohol use and interpersonal violence: alcohol detected in homicide victims. Am J Public Health 76:144-149.

Gorman DM, Labouvie EW, Speer PW, Subaiya AP (1998a) Alcohol availability and domestic violence. Am J Drug Alcohol Abuse 24:661-673.

Gorman DM, Speer PW, Labouvie EW, Subaiya AP (1998b) Risk of assaultive violence and alcohol availability in New Jersey. Am J Public Health 88:97-100.

Graham K, Bernards S, Osgood D, Wells S (2006) Bad nights or bad bars? Multi-level analysis of environmental predictors of aggression in late-night large-capacity bars and clubs. Addiction 101:1569-1580.

Graham K, Homel R (1997) Creating safer bars, in Alcohol: Minimizing the Harm (Plant M, Single E, Stockwell T eds), pp 171-192. Free Association Books, London.

Graham K, La Rocque L, Yetman R, Ross TJ, Guistra E (1980) Aggression and barroom environments. J Stud Alcohol 41:277-292.

Grassel KM, Wintemute GJ, Wright MA, Romero MP (2003) Association between handgun purchase and mortality from firearm injury. Inj Prev 9:48-52.

Grossman DC, Mueller BA, Kenaston T, Salzberg P, Cooper W, Jurkovich GJ (1996) The validity of police assessment of driver intoxication in motor vehicle crashes leading to hospitalization. Accid Anal Prev 28:435-442.

Groves R (2006) Nonresponse rates and nonresponse bias in household surveys. Public Opin Q 70:646-675.

Gruenewald P (2007) The spatial ecology of alcohol problems: niche theory and assortative drinking. Addiction 102:870-878.

Gruenewald PJ, Freisthler B, Remer L, Lascala EA, Treno A (2006) Ecological models of alcohol outlets and violent assaults: crime potentials and geospatial analysis. Addiction 101:666-677.

Gruenewald P, Remer L (2006) Changes in outlet densities affect violence rates. Alcohol Clin Exp Res 30:1184-1193.

Haddon W Jr, Valien P, Mc CJ, Umberger CJ (1961) A controlled investigation of the characteristics of adult pedestrians fatally injured by motor vehicles in Manhattan. J Chronic Dis 14:655-678.

Harlow BL, Crea EC, East MA, Oleson B, Fraer CJ, Cramer DW (1993) Telephone answering machines: the influence of leaving messages on telephone interviewing response rates. Epidemiology 4:380-383.

Herzog A, Rodgers W (1992) The use of survey methods in research on older Americans, in The Epidemiologic Study of the Elderly (Woolson R ed.), Oxford University Press, New York, NY.

Holder HD, Gruenewald PJ, Ponicki WR, Treno AJ, Grube JW, Saltz RF, Voas RB, Reynolds R, Davis J, Sanchez L, Gaumont G, Roeper P (2000) Effect of community-based interventions on high-risk drinking and alcoholrelated injuries. JAMA 284:2341-2347.

Holt D, Steel D, Tranmer M (1996) Areal homogeneity and the modifiable areal unit problem. Geogr Syst 3:181-200.

Islam SS, Edla SR, Mujuru P, Doyle EJ, Ducatman AM (2003) Risk factors for physical assault. State-managed workers' compensation experience. Am J Prev Med 25:31-37.

Kassirer JP (1995) A partisan assault on science - the threat to the CDC. N Engl J Med 333:793-794.

Keeter S, Kennedy C, Dimock M, Best J, Craighill P (2006) Gauging the impact of growing nonresponse on estimates from a National RDD Telephone Survey. Public Opin Q 70:759-779. 
Kellermann AL, Rivara FP, Rushforth NB, Banton JG, Reay DT, Francisco JT, Locci AB, Prodzinski J, Hackman BB, Somes G (1993) Gun ownership as a risk factor for homicide in the home. N Engl J Med 329:1084-1091.

Kleck G (1998) What are the risks and benefits of keeping a gun in the home? JAMA 280:473-475.

Kleck G, DeLone M (1993) Victim resistance and offender weapon effects in robbery. J Quant Criminol 9:55-81.

Kleck G, Gertz M (1995) Armed resistance to crime: the prevalence and nature of self-defense with a gun. J Crim Law Criminol 86:150-187.

Kleck G, Gertz M (1998) Carrying guns for protection: results from the National Self-Defense Survey. J Res Crime Delinq 35:193-224.

Kleck G, McElrath K (1991) The effects of weaponry on human violence. Soc Forces 69:669-692.

Koepsell TD, McGuire V, Longstreth WT Jr, Nelson LM, van Belle G (1996) Randomized trial of leaving messages on telephone answering machines for control recruitment in an epidemiologic study. Am J Epidemiol 144:704 706.

Krieger N, Chen JT, Waterman PD, Soobader MJ, Subramanian SV, Carson R (2002) Geocoding and monitoring of US socioeconomic inequalities in mortality and cancer incidence: does the choice of area-based measure and geographic level matter? The Public Health Disparities Geocoding Project. Am J Epidemiol 156:471-482.

Livingston M (2008) Alcohol outlet density and assault: a spatial analysis. Addiction 103:619-628.

Livingston M, Chikritzhs T, Room R (2007) Changing the density of alcohol outlets to reduce alcohol-related problems. Drug Alcohol Rev 26:557-566.

Longley P, Goodchild M, Maguire D, Rhind D (2005) Geographical Information Systems and Science, 2nd edn. John Wiley \& Sons, New York.

MacAndrews C, Edgerton R (1969) Drunken Comportment, a Social Explanation. Aldine, New York.

McCord E, Ratcliffe J (2007) A micro-spatial analysis of the demographic and criminogenic environment of drug markets in Philadelphia. Aust $\mathrm{N} \mathrm{Z} \mathrm{J}$ Criminol 40:43-63.

Morgenstern H (1998) Ecologic studies, in Modern Epidemiology, 2nd edn (Rothman J, Greenland S eds), pp 459-480. Lippincott Williams \& Wilkins, Philadelphia, PA.

Moskowitz H, Burns M, Ferguson S (1999) Police officers' detection of breath odors from alcohol ingestion. Accid Anal Prev 31:175-180.

Nelson DE, Grant-Worley JA, Powell K, Mercy J, Holtzman D (1996) Population estimates of household firearm storage practices and firearm carrying in Oregon. JAMA 275:1744-1749.

Openshaw S (1984) The modifiable areal unit problem. Concepts Tech Mod Geogr 38:41-54.

Parker RN, Rebhun LA (1995) Alcohol and Homicide; A Deadly Combination of Two American Traditions. pp 1-185. State University of New York, New York.

Pernanen K (1991) Alcohol in Human Violence. Guilford Press, New York.

Poole C (1986) Exposure opportunity in case-control studies. Am J Epidemiol 123:352-358.

Poole C (1987) Critical appraisal of the exposure-potential restriction rule. Am J Epidemiol 125:179-183.

Poole C (1999) Controls who experienced hypothetical causal intermediates should not be excluded from case-control studies. Am J Epidemiol 150:547551.

Quigley BM, Leonard KE, Collins RL (2003) Characteristics of violent bars and bar patrons. J Stud Alcohol 64:765-772.

Reedy DC, Koper CS (2003) Impact of handgun types on gun assault outcomes: a comparison of gun assaults involving semiautomatic pistols and revolvers. Inj Prev 9:151-155.

Richmond TS, Branas CC, Cheney RA, Schwab CW (2004) The case for enhanced data collection of gun type. J Trauma 57:1356-1360.

Roberts I (1995) Methodologic issues in injury case-control studies. Inj Prev 1:45-48.

Romelsjo A (1995) Alcohol consumption and unintentional injury, suicide, violence, work performance, and inter-generational effects, in Alcohol and
Public Policy. Evidence and Issues (Holder HD, Edwards G eds), pp 114 134. Oxford University Press, New York, NY.

Roncek D, Bell R (1982) Bars, blocks, and crimes. J Environ Sys 11:35-74.

Roncek D, Maier R (1991) Bars, blocks, and crimes revisited: linking the theory of routine activities to the empiricism of "hot spots." Criminology 29:725-753.

Rothman KJ, Greenland S (1998) Case-control studies, in Modern Epidemiology, 2nd edn (Rothman KJ, Greenland S eds), pp 93-114. Lippincott Williams \& Wilkins, Philadelphia, PA.

Rubin D (1987) Multiple Imputation for Nonresponse in Surveys. Wiley, New York.

Scribner R (2000) Small Area Analysis and GIS Technology: Incorporating Group Level Effects Into Explanatory Models. National Institutes of Health, Bethesda, MD.

Scribner R, Cohen D, Kaplan S, Allen SH (1999) Alcohol availability and homicide in New Orleans: conceptual considerations for small area analysis of the effect of alcohol outlet density. J Stud Alcohol 60:310-316.

Scribner RA, MacKinnon DP, Dwyer JH (1995) The risk of assaultive violence and alcohol availability in Los Angeles County. Am J Public Health 85:335-340.

Silverman B (1978) Choosing a window width when estimating a density. Biometrika 65:1-11.

Silverman B (1986) Density Estimation. Chapman and Hall, New York.

Soderstrom CA, Dailey JT, Kerns TJ (1994) Alcohol and other drugs: an assessment of testing and clinical practices in U.S. trauma centers. J Trauma 36:68-73.

Speer P, Gorman D, Labouvie E, Ontkush M (1998) Violent crime and alcohol availability: relationships in an urban community. J Public Health Policy 19:303-318.

Stevenson M, McClure R (2005) Use of ecological study designs for injury prevention. Inj Prev 11:2-4.

Stuster J, Burns M (1998) Validation of the Standardized Field Sobriety Test Battery at BACs Below 0.10 Percent. Final Report. US Department of Transportation, National Highway Traffic Safety Administration, Washington, DC.

Teret SP, Wintemute GJ (1993) Policies to prevent firearm injuries. Health Aff 12:96-108

Treno A, Gruenewald P, Remer L, Johnson F, LaScala E (2007) Examining multi-level relationships between bars. hostility and aggression: social selection and social influence. Addiction 103:66-77.

Wacholder S, McLaughlin JK, Silverman DT, Mandel JS (1992) Selection of controls in case-control studies. I. Principles. Am J Epidemiol 135:10191028.

Waksberg J (1978) Sampling methods for random digit dialing. J Am Stat Assoc 73:40-46.

Warner BD, Wilson Coomer B (2003) Neighborhood drug arrest rates: are they a meaningful indicator of drug activity? A research note. J Res Crime Delinq 40:123-138.

Weiner JW, Wiebe DJ, Richmond TS, Beam K, Berman AL, Branas CC, Cheney RA, Coyne-Beasley T, Firman J, Fishbein M, Hargarten S, Hemenway D, Jeffcoat R, Kennedy D, Koper CS, Lemaire J, Miller M, Roth JA, Schwab CW, Spitzer R, Teret S, Vernick J, Webster D (2007) Reducing firearm violence: a research agenda. Inj Prev 13, 80-84.

Wells W (2002) The nature and circumstances of defensive gun use: a content analysis of interpersonal conflict situations involving criminal offenders. Justice Q 19:127-157.

White H (1980) A heteroscedasticity-consistent covariance matrix estimator and a direct test for heteroscedasticity. Econometrica 48:817-830.

Wiebe DJ (2003) Homicide and suicide risks associated with firearms in the home: a national case-control study. Ann Emerg Med 41:771-782.

Wiebe DJ, Branas CC (2003) Bias when using dead controls to study handgun purchase as a risk factor for violent death. Inj Prev 9:381382.

Wiebe DJ, Branas CC, Berlin JA, Morgenstern H (2004) Correcting for bias in case-control studies using non-population-based subjects as controls. Am J Epidemiol 159:S54. 
van Wijngaarden M, Cushing B, Kerns T, Dischinger P (1995) Police perception of intoxication among injured pedestrians. J Emerg Med 13:21-26.

Williamson D, McLafferty S, Goldsmith V (1998) Smoothing Crime Incident Data: New Methods for Determining Bandwidth in Kernel Estimation. Paper presented at the Environmental Systems Research Institute International Conference Papers, Washington, DC.

Wintemute GJ (1999) The future of firearm violence prevention: building on success. JAMA 282:475-478.

Wolfson M, Toomey TL, Forster JL, Wagenaar AC, McGovern PG, Perry CL (1996) Characteristics, policies and practices of alcohol outlets and sales to underage persons. J Stud Alcohol 57:670-674.
Wong D (1991) The modifiable areal unit problem in multivariate statistical analysis. Environ Plan A 23:1025-1034.

Wrigley N (1995) Revisiting the modifiable areal unit problem and ecological fallacy, in Diffusing Geography (Cliff A, Gould P, Hoare A, Thrift N eds), pp 123-181. Blackwell Scientific, Oxford, UK.

Ziegenhagen E, Brosnan D (1985) Victim responses to robbery and crime control policy. Criminology 23:675-695.

Zimring FE (1991) Firearms, violence, and public policy. Scientific American 265:48-54. 